\title{
RLBP Metodu ile Mamografi Görüntülerinin İncelenmesi ve Sınıflandırılması
}

\author{
Muhammed Mustafa Kelek ${ }^{1}$, Enes Cengiz ${ }^{2}$, Yüksel Oğuz ${ }^{1}$, Ahmet Yönetken $^{3}$ \\ ${ }^{1}$ Afyon Kocatepe Üniversitesi, Teknoloji Fakültesi, Elektrik Elektronik Mühendisliği, Afyonkarahisar \\ 2, Afyon Kocatepe Üniversitesi, Teknoloji Fakültesi, Mekatronik Mühendisliği, Afyonkarahisar \\ ${ }^{3,}$ Afyon Kocatepe Üniversitesi, Mühendislik Fakültesi, Elektrik Mühendisliği Bölümü, Afyonkarahisar \\ e-mail: mmustafakelek@aku.edu.tr, ORCID ID: https://orcid.org/0000-0002-9915-4776 \\ e-mail: enescengiz@aku.edu.tr, ORCIDID: https://orcid.org/0000-0003-1127-2194 \\ e-mail: yukseloguz@aku.edu.tr, ORCID ID: https://orcid.org/0000-0002-5233-151X \\ e-mail: yonetken@aku.edu.tr, ORCID ID: http://orcid.org/0000-0003-1844-7233
}

Geliş Tarihi: 03.08.2021; Kabul Tarihi: 01.09.2021

Öz
Göğüs kanseri dünya genelinde kadınlarda en çok karşılaşılan kanser türüdür. Günümüzde her kadının
başına gelebilecek olan göğüs kanseri, erkeklerde de görülebilmektedir. Göğüs kanserinde insanların
fiziksel ve zihinsel halleri çok etkilidir. Göğüs kanserine karşın tedbirli olabilmek için belirli aralıklarla
göğüs dokularının incelenmesi gerekmektedir. Bu dokular, uzmanlar tarafından incelenmektedir. Ancak
inceleme esnasında yapılan yanlış teşhisler tedavi sürecini olumsuz etkilemektedir. Bu sebeple, bu
dokuların sayısal ortamda işlenip incelenmesi daha faydalı olmaktadır. Bu çalışmada, YSA ile göğüs
kanserinin sınıflandırması yapılmışıtır. Mamografi görüntüleri üzerinde Döndürülmüş Yerel İkili Örüntü
(RLBP) metodu kullanılarak öznitelikler çıkarılmıştır. Bu öznitelikler, parametreleri belirlenmiş olan YSA
aracılığı ile eğitilmiştir. Eğitim sonucunda iyi ve kötü huylu olarak sınıflandırılan ikili sınıflandırmada
\%87,82 ve Yağlı, Yağlı-Glandüler ve Yoğun-Glandüler olarak sınıflandırılan üçlü arka plan doku
sınıflandırmasında \%80,95 başarı oranı elde edilmiştir.

\section{Examination and Classification of Mammography Images with the RLBP Method}

\begin{abstract}
Breast cancer is the most common type of cancer in women worldwide. Breast cancer, which can happen to every woman, can also be seen in men. The physical and mental state of people is very important in breast cancer. The breast tissues should be examined at intervals in order to be cautious against breast cancer. The breast tissues should be examined periodically in order to be cautious against breast cancer. These tissues are examined by experts. However, misdiagnoses made during the examination adversely affect the treatment process. For this reason, it is more beneficial to process and examine these tissues in digital environment. In this study, classification of breast cancer was made with ANN. Features were extracted using the Rotated Local Binary Pattern (RLBP) method on mammography images. These features were trained by ANN whose parameters have been determined. As a result of the training, a success rate of $87.82 \%$ was achieved in the binary classification classified as benign and malignant, and $80.95 \%$ in the triple background tissue classification classified as Fatty, FattyGlandüler and Dense-Glandüler.
\end{abstract}

Keywords

Mammogram; Artificial Neural Network (ANN); RLBP; Breast Cancer. 


\section{Giriş}

Kanser çağımızın en tehlikeli ve ölümcül hastalıklarından birisidir. Kanserde erken tanı, teşhis ve tedavi ciddi önem arz etmektedir. Göğüs kanseri ise, kadınlar arasında çok rastlanan kanser tipidir. Ancak sadece kadınlarda değil erkeklerin de göğüs kanserine yakalanma ihtimalleri vardır (Hossfeld 1992, Topuz at al 2003). Kanser, hücrelerde çevresel ve kalıtsal nedenlerden dolayı DNA'nın hasar alması sonucu, hücrelerin kontrolsüz veya anormal bir şekilde büyümesi ve çoğalmasıdır. Dünyada genelinde kadınlardaki kansere bağıı ölüm oranlarında en yüksek orana sahip olan göğüs kanseridir. Teknolojinin gelişmesiyle birlikte erken tanıda eski dönemler ile kıyaslandığında gözle görülebilir bir gelişme vardır. Tıbbi görüntüleme, bir bozukluğu teşhis etmek, izlemek veya tedavi etmek, insan vücudunu analiz etmek için kullanılan belirli teknikleri ifade eder. Bazı araştırmacılar, hastalıkları tanımlamak için tıbbi görüntülerin üretimi ve yorumlanmasına yoğun bir şekilde odaklanmaktadır. Yapay zekâ tıbbi görüntülerin analizi gibi tıbbi alanda rol oynayarak son yıllarda önemli ilerleme kaydetti. Erken teşhiste hekim muayenesi, tıbbi görüntüleme olan göğüs ultrasonografisi ve iki taraflı mamografi ile göğüslerin kansere karşı etkin bir şekilde incelenmesi mümkündür. Mamografi, erken teşhiste etkin bir metot olarak bilinmektedir (Baldi et al. 2003, Houssein et al. 2020, Society 2019). Mamografi düşük miktarda X-ray ışını kullanarak görüntüleri oluşturmaktadır. Başarısını kanıtlamış olan mamografi görüntüleri ile göğüs kanserinden kaynaklanan ölüm oranlarının düştüğü gözlemlenmiştir (Humprey et al. 2009, Kopans and Feig 1993). Literatürde yer alan bilgiler incelendiğinde; dünyada her üç dakikada bir kadına göğüs kanseri tanısı konulduğu ifade edilmektedir (Howlader et al. 2012, Klarenbach et al. 2018). Mamografi görüntüleri incelenerek kanserin hangi aşamada olduğu ve kanserin şiddeti (iyi - kötü) belirlenebilmektedir. Uzmanların görüntüleri incelerken tanı koyma esansında çeşitli hatalar yaptığı ve bu hataların tedavi sürecini olumsuz etkilediği görülebilmektedir (Smith et al. 2001).
Mamografideki kitlelerin özellikleri, boyutu ve şekli büyük ölçüde değişir. Bu nedenle, birçok bilgisayar tekniği, mamografi görüntülerinde kitlelerin tespiti için çok ölçekli kavramları kullanmıştır.

Brzakovic ve Neskovic, kitle lokalizasyonu için bulanık piramit bağlantısı önerdiler ve konumlarına göre, görüntünün çeşitli çözünürlük seviyelerinde kenar piksellerin yoğunluk bağlantılarını kullandılar (Brzakovic and Neskovic 1994). Miller ve Ramsey Doğrusal olmayan çok ölçekli yaklaşımı kullanarak, tarama veri setindeki kötü huylu tümörlerini saptamada \%85 doğruluk elde etmiştir (Miller and Ramsey 1996). Chang ve Laine lezyonları analiz etmek üzere kullanılacak görsel ipuçlarını sağlamak ve özellikleri arttırmak için çok boyutlu analiz prosedüründe tutarlılık ve yönelim ölçümlerini kullandılar (Chang and Laine 1999). Petrick ve arkadaşları 14 adet benign ve 11 adet kötü huylu vakayı içeren 25 mamografinin bir veri setini kullanarak kitlelerin tespiti için bir Laplacian-ofGaussian kenar dedektörü ile birlikte iki aşamalı bir adaptif yoğunluk ağırlıklı kontrast geliştirme filtresinin kullanılmasını bildirdiler (Petrick et al 1996). Çalışmalarında Marcano-Cedeño ve ark. 2011'de göğüs kanserinin sınıflandırılması için YSA kullanan bir model sundular (Marcano-Cedeño et al. 2011). Yöntemlerini Wisconsin göğüs kanseri veri setinde (WBCD) test ederek geri yayılımlı çok katmanlı perseptron sinir ağları ile karşılaştırdılar. Bhardwaj ve Tiwari'de 2015 yılında, WBCD veri setini kullanarak göğüs kanseri sınıflandırma problemini sinir ağları tekniğine dayalı olarak çözmek için bir yöntem önermişlerdir (Bhardwaj and Tiwari 2015). Mahersia ve ark nöro-bulanık ile yapay sinir ağı (YSA) kullanan kitle algılama sistemi oluşturmuşlardır (Mahersia et al 2016). Mias görüntü veri seti ile gerçekleştirdikleri sistemi kullanarak $\% 97,08^{\prime}$ lik yüksek bir performans elde ettiklerini ifade etmişlerdir. Singh ve Urooj ve Xie ve ark göğüs kanseri tümörünü sınıflandırmak için aşırı makine öğrenmesi ve dalgacık YSA hibrit şekilde kullanarak YSA kullanmışlardır (Singh and Urooj 2016, Xie et al. 2016). Göğüs kanserinin sınıflandırma için Mias ve DDSM veri setlerini kullanmışlardır. 
$\mathrm{Bu}$ çalışmanın birinci bölümde göğüs kanserinin önemi ve daha önce yapılan literatürdeki akademik çalışmalardan bahsedilmiştir. íkinci bölümünde görüntü özellik çıkarımı için kullanılan yerel ikili desenin (LBP) ve YSA'nın çalışma mantığı aktarılmıştır. Çalışmada kullanılan Mias veri seti de detaylı şekilde tanıtılmıştır. Oluşturulan YSA ile Mias veri setinde elde edilen performans yine bu bölümde verilmiştir. Üçüncü bölümde ise elde edilen sonuçların genel olarak sunulması yer almaktadır.

\section{Materyal ve Metot}

\subsection{Döndürülmüş Yerel Ikili Örüntü (Rotated Local Binary Pattern - RLBP)}

LBP, her pikselin yerel komşuluk değerlerine dayalı olarak görüntünün piksellerini etiketleyen bir özellik çıkarma metodudur. Literatüre ilk olarak Ojala ve arkadaşları tarafından 1996 yılında girmiştir (Ergene et al. 2016). Matematiksel basitliği ve hızlı olması nedeniyle oldukça tercih edilmektedir. LBP, ayırt etme gücü, ışığa karşı duyarsızlı̆̆ı ve hesaplama kolaylığı nedeniyle çeşitli uygulamalarda popüler bir yaklaşım haline gelmiştir. En önemli özelliği, gri seviyedeki ışık değişikliklere dayanıkı olmasıdır. Buda tanıma yöntemlerinde oldukça popüler olmasını sağlamaktadır. 3B boyutlu görüntü sınıflandırmada, yüz tanımada, yaş belirleme, arka plan modelleme gibi çeşitli kullanım alanları bulunmaktadır (Ergene et al. 2016, Ojala et al. 1996, Zahran et al. 2018, Kaymak et al. 2017). Bir diğer önemli özelliği ise gerçek zamanlı çalışmalarda zorlu görüntüleri analiz etmeyi mümkün kılan hesaplama basitliği olmasıdır. LBPP, $R$ şeklinde gösterimi bulunan yöntemde $P$ merkez piksel etrafından alınacak olan komşu piksellerin sayısını ve $R$ ise örnek sayısını temsil etmektedir.

Bu metot, merkez pikselin komşu pikseller ile olan ilişkilerine bakılmaktadır. Merkez piksel ve komşu pikseller arasındaki farklar $\mathrm{u}(\mathrm{x})$ birim basamak fonksiyonu ile etiketlenmektedir. Bu ikili tabandaki etiketin onluk tabanı merkezdeki pikselin yerel değerini verir. LBP'nin matematiksel formülü Denklem 1 ve 2'de verilmiştir.

$$
\begin{aligned}
& L B P_{P, R}\left(x_{c}\right)=\sum_{i=0}^{P-1} u\left(x_{p}-x_{c}\right) 2^{p} \\
& u(y)= \begin{cases}1, & y \geq 0 \\
0, & y<0\end{cases}
\end{aligned}
$$

Bu denklemdeki xc: Merkez piksel, xp: Komşu pikselleri, R: Komşu piksellerin merkez piksele uzaklığını ve P: İşleme sokulan komşu piksel sayısını verir. Şekil 1'de merkez piksele LBP metodunun uygulanması gösterilmiştir. Çıktı olarak elde edilen değerin hesaplanmasında ikilik taban saat yönünde alınmıştır.

\begin{tabular}{|l|l|l|}
\hline 47 & 51 & 65 \\
\hline 62 & 70 & 70 \\
\hline 80 & 83 & 78 \\
\hline \multicolumn{3}{|c|}{ Örnek } \\
\hline
\end{tabular}

\begin{tabular}{|c|c|c|}
\hline 1 & 2 & 4 \\
\hline 128 & & 8 \\
\hline 64 & 32 & 16 \\
\hline \multicolumn{2}{|c|}{ ikili taban } \\
\hline
\end{tabular}

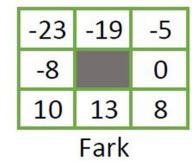

\begin{tabular}{|l|l|l|}
\hline 0 & 0 & 0 \\
\hline 0 & & 1 \\
\hline 1 & 1 & 1 \\
\hline \multicolumn{3}{|c}{ Eşik }
\end{tabular}

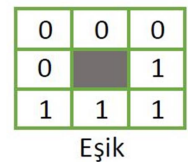

LBP Tekniği

120
Şekil 1. LBP’nin matematiksel hesaplanmasının örneği

RLBP tekniğinde, LBP'deki işlemlerin aynısı uygulanmaktadır. En son çıktı olarak elde edilen ikilik tabandaki sayının minimum olanı bularak onun seçilmesini RLBP sağlamaktadır. Yukarıdaki örnekte LBP tekniği ile elde edilen 240 değeri, RLBP tekniğinde ise $15^{\prime}$ dir. Yapılan döndürme işlemi Şekil

\begin{tabular}{|c|c|c|c|c|c|c|c|c|}
\hline 1 & 2 & 4 & \multirow{3}{*}{$\mathrm{x}$} & 1 & 1 & 1 & \multirow{3}{*}{$=$} & RLBP Tekniğ \\
\hline 128 & & 8 & & 0 & & 1 & & 15 \\
\hline 64 & 32 & 16 & & 0 & 0 & 0 & & \\
\hline
\end{tabular}
2 'de gösterilmiştir.

Şekil 2. RLBP’nin matematiksel hesaplanmasının örneği

Göğüs kanserinin tümörlü olup olmadığının $(0,1)$ sınıflandırması için veri setinde yer alan görüntülere RLBP metodu uygulanmıştır. RLBP yöntemi ile görüntü verileri daha anlamlı hale getirilerek öz nitelikleri çıkartılmıştır. Çalışmada kullanılan MiAS veri tabanındaki görüntüler $1024 \times 1024$ boyutunda olup RLBP yöntemi sonucunda $1024 \times 1$ boyutunda bir vektöre dönüştürülmektedir.

\subsection{Yapay Sinir Ağları (YSA)}

Canlı vücudunda bir sinir hücresinin yapı olarak dentrit, gövde ve aksonlardan oluştuğu bilinmektedir. Bu yapının matematiksel olarak modellenmesi ile yapay zekâ öğrenme algoritmalarından yapay sinir ağları meydana gelmiştir. Bir sinir hücrenin taklit edilmesi ile Yapay Sinir Hücresi (YSH) elde edilir. Bir veya daha fazla yapay sinir hücresinin paralel olarak kullanılması ile 
elde edilen yapıya Yapay Sinir katmanı denir. Şekil 3'te örnek bir sinir ağı katmanı gösterilmiştir. Katmanların seri olarak birbirine bağlanmasından oluşan yapıya da YSA denir. Böylece canlı vücudunda gözlemlenen sinir ağının küçük bir parçası modellenmiş olur.

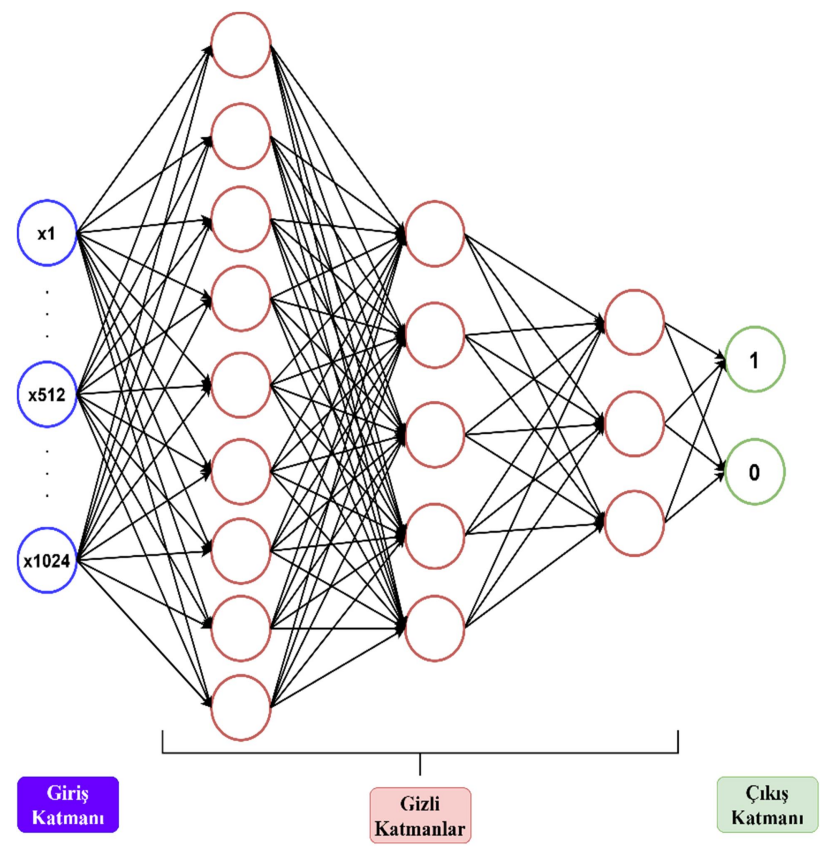

Şekil 3. Yapay sinir ağı örnek gösterimi

Bir YSH'de Şekil 3'e göre çalışma parametrelerine uygun istenilen miktarda giriş kullanılabilir. Gövde olarak bir adet Aktivasyon Fonksiyonu bulunmaktadır. Aktivasyon fonksiyonu bu YSH'nin, ona verilen değerleri uygulamaya aldığı bir matematiksel fonksiyondur. Bu fonksiyondan elde edilen sonuç YSH'nin çıkış değeridir. Böylece gerçek bir hücredeki aksonda modellenmiş olur.

Girişlere verilen veri dizisi, her birine ait olan ağırlıkla çarpılarak toplam fonksiyonlarına gönderilir. Bu fonksiyonlardan elde edilen değerler aktivasyon fonksiyonlarına gönderilir. Buradan elde edilen sonuçlar çıkış değerleri dizisini oluşturur.

Aktivasyon fonksiyonu, sürekli ve türevi belirlenebilen herhangi bir $\mathrm{F}$ fonksiyonu olabilir. Hataya bağıı olarak ağırlıkların güncellenmesi için geriye yayılım yöntemiyle hesap yapılırken aktivasyonu fonksiyonunun türevi alınır olması gerekir. YSA da birçok çalışma incelendiğinde lineer ve sigmoid fonksiyonların kullanıldığı karşımıza çıkmaktadır. Çalışmada kullanılan YSA giriş, çıkış ve 3 gizli katmana sahiptir.

Bir YSA'nın kullanılabilmesi için önce sistemin eğitilmesi, sonra performansının ölçülerek yeterli eğitimin sağlanıp sağlanmadığının test edilmesi gerekir. İlk aşamada giriş ve çıkış için kullanılacak verilerin tür ve adetlerinin belirlenmesi, kullanılacak örnek verilerin toplanması gerekir. Elde edilen veriler YSA eğitiminde kullanmak için uygun olmayabilirler. $\mathrm{Bu}$ gibi durumlarda verilerin, normalizasyon, özellik çıkarımı gibi çeşitli işlemlerden geçirilerek kullanıma uygun hale getirilmeleri gerekmektedir. Sonraki aşamalarda eğitim ve test için kullanılacak verilerin ayrıştırılması önemlidir. Örnekler arasından seçilecek eğitim ve test verilerinin seçim aşamaları değerlendirme açısından önemlidir. Daha sonra eğitimin ve testin gerçekleştirilmesi aşamasına geçilebilir. Yeterli başarının elde edilmesi ile hazırlanan YSA, uygulamalarda kullanıma hazır hale gelmektedir (Cengiz et al. 2021).

\subsection{Mias Veri Tabanı}

Bu çalışmada, Mamografik Görüntü Analiz Derneği (MIAS) veri tabanından alınan mamogram görüntüleri üzerinde incelemeler yapılmıştır. Veri tabanında toplamda 322 adet görüntü bulunmaktadır. Bu görüntülüler 1024×1024 piksel boyutundadırlar. Kullanılan verilerde arka plan dokusuna (yağı(Y), yağlı-glandüler(YG), yoğunglandüler(YoG)) ve anormalliğin şiddeti (iyi huylu ya da kötü huylu) gibi çeşitli özelliklerin etiketlenmesi verilmiştir (Maaenpaaa and Pietikaainen 2004). Şekil 4' te yağlı-glandüler (a), yağlı (b) ve yoğunglandüler (c) doku özellikleri verilmiştir.

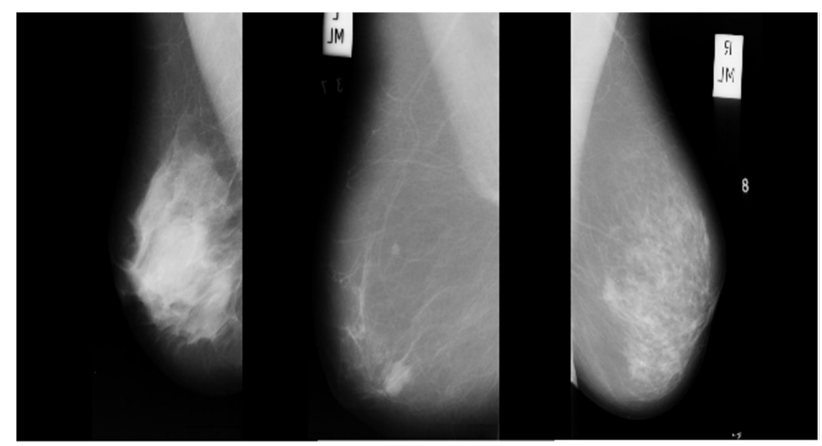

(a)

(b)

(c)

Şekil 4. Yağlı-glandüler (a), Yağlı (b) ve Yoğun-glandüler (c) mamografik görüntüler

İyi huylu (a) ve Kötü huylu (b) kist görüntüleri Şekil 5 'te verilmiştir. 


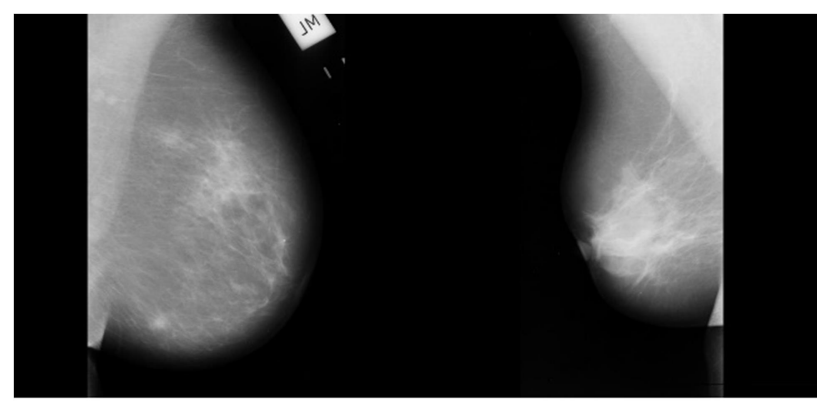

(a)

(b)

Şekil 5. İyi huylu (a) ve Kötü huylu (b) mamografik görüntüler

\subsection{Uygulama Sonuçları}

Mamografi görüntülerinin YSA'da kullanılması için ilk önce özniteliklerinin çıkarılarak giriş ve çıkış veri setinin düzenlenmesi gerekir. RLBP yöntemi ile veri tabanında yer alan görüntülerin öznitelikleri çıkartılmıştır. 1024x1 boyutunda olan bu öz nitelik vektörü YSA modeline giriş olarak verilmiş̧ir. YSA modelinin çıkışında ise iki farklı kategoride sınıflandırma yapılmıştır. Bunlardan birincisi göğüs kanseri tümörünün iyi huylu veya kötü huylu olup olmadığının sınıflandırılmasıdır. Diğer sınıflandırma kategorisi ise arka plan dokusuna göre (yağlı, yağ|ıglandüler ve yoğun-glandüler) yapılan sınıflandırmadır. YSA modelinde sırasıyla toplam görüntülerin yaklaşık $\% 85$ 'i eğitim ve $\% 15^{\prime} i$ test olacak şekilde ayrılmıştır. Bu aşamadan sonra eğitim için YSA modeli oluşturulur. Matlab ortamında gerçekleştirilen eğitim işlemi için sırasıyla 9,5 ve 3 nörona sahip 3 gizli katman kullanılarak model oluşturulmuştur. Eğitim işleminin ardından test veri seti ile test işlemi gerçekleştirilerek YSA'nın çalışma performansı gözlemlenmiştir. Tablo 1'de yapılan çalışmanın sonuçları verilmiştir.

Tablo 1. îki farklı tip sınıflandırmanın başarı sonuçları.

\begin{tabular}{ccc}
\hline & $\begin{array}{c}\text { i-K Huylu } \\
\text { Sinıflandırması }\end{array}$ & $\begin{array}{c}\text { Y-YG-YoG } \\
\text { sınıflandırması }\end{array}$ \\
\hline Veri Sayısı & 115 & 322 \\
\hline $\begin{array}{c}\text { Doğru tahmin } \\
\text { edilen veri sayısı }\end{array}$ & 101 & 260 \\
\hline $\begin{array}{c}\text { Yanlış tahmin } \\
\text { edilen veri sayısı }\end{array}$ & 14 & 62 \\
\hline Başarı Oranı (\%) & 87,82 & 80,95 \\
\hline
\end{tabular}

\section{Sonuçlar}

Yapılan bu çalışmada RLBP metodu kullanılarak mamografi görüntülerin öznitelikleri çıkarılmıştır. Çıkarılan öznitelikler, yapay sinir ağlarına giriş olarak verilmiştir. MIAS veri setinde toplamda 322 görüntü verisi bulunmaktadır. Bu verilerin $\% 85^{\prime} i$ (280 adet veri) YSA eğitimi için kullanılmış olup geriye kalan \%15'i (42 adet veri) ise test aşamasında kullanılmıştır. Yapılan doku sınıflandırmasında (Yağlı, Yağlı-Glandüler, YoğunGlandüler) \%80,95'lik bir başarı elde edilmiştir. Kullanılan veri setinde iyi huylu - kötü huylu kist sınıflandırmasında 115 adet veri bulunmaktadır. Bu verilerden 100 tanesi eğitim için kalan 15 tanesi ise test için kullanılmıştır. Yapılan iyi - kötü huylu sınıflandırmada ise $\% 87,82^{\prime}$ lik bir sonuç elde edilmiştir. Bilgisayar teknolojileri ile elde edilen bu başarı oranları mamografi görüntülerindeki oluşumun fark edilmesinde ve iyi - kötü huylu olmasının belirlenmesinde sağlık personellerine yardımcı olacağı düşünülmektedir.

\section{References}

Baldi, V. Cicalese, A. Coppala, G. Scarano, M. Gatto, E, 2003. Results of Mammographic Screening.

Bhardwaj, A., and Tiwari, A, 2015. Breast cancer diagnosis using genetically optimized neural network model. Expert Systems with Applications, 42(10), 4611-4620.

Brzakovic D. and Neskovic M., 1994.Mammogram screening using multiresolution- based image segmentation, in State of the Art in Digital Mammographic Image Analysis, K.W. Bowyer and S. Astley, Eds, Singapore: World Scientific, 103-127.

Cengiz, E., Yılmaz, C., \& Kahraman, H., 2021. Classification of Human and Vehicles with The Deep Learning Based on Transfer Learning Method. Düzce Üniversitesi Bilim ve Teknoloji Dergisi, 9(3), 215-225.

Chang C. M. and Laine A., 1999. Coherence of multiscale features for enhancement of digital mammograms, IEEE Trans. Inform. Technol. Biomed., 3, 32-46.

Ergene, Mehmet Celalettin, Akif Durdu, and Halil Cetin, 2016. Imitation and learning of human hand gesture 
tasks of the 3D printed robotic hand by using artificial neural networks. Electronics, Computers and Artificial Intelligence (ECAI), 2016 8th International Conference on. IEEE.

Hossfeld, DK, 1992. Manual of Clinical Oncology, 5th ed. Springer- Verlag, UICC.

Houssein, E. H., Emam, M. M., Ali, A. A., and Suganthan, P. N., 2020. Deep and machine learning techniques for medical imaging-based breast cancer: $A$ comprehensive review, Expert Systems with Applications, 114161.

Howlader, N. Noone, AM. Krapcho, M. et. al. (eds), 2012. SEER Cancer Statistics Review, 1975-2009

Humprey, LL. Helfand, M. Chang, BK. Woolf, SH, 2009. Breast cancer screening: a summary of the evidence for the U.S Preventive Services Task Force.

Kaymak, S., Helwan, A., \& Uzun, D.,2017. Breast cancer image classification using artificial neural networks. Procedia computer science, 120, 126-131.

Klarenbach, S., Sims-Jones, N., Lewin, G., Singh, H., Thériault, G., Tonelli, M., ... \& Thombs, B. D. 2018. Recommendations on screening for breast cancer in women aged 40-74 years who are not at increased risk for breast cancer. Cmaj, 190(49), 1441-1451.

Kopans, D.B. Feig, S.A, 1993. The Canadian National Breast Cancer Screening Study.

Maaenpaaa T., Pietikaainen M., 2004. Texture Analysis with Local Binary Patterns, University of Oulu,

Mahersia, H., Boulehmi, H., and Hamrouni, K., 2016. Development of intelligent systems based on Bayesian regularization network and neuro-fuzzy models for mass detection in mammograms: An comparative analysis. Computer Methods and Programs in Biomedicine, 126, 46-62.

Marcano-Cedeño, A., Quintanilla-Domínguez, J., and Andina, D., 2011. WBCD breast cancer database classification applying artificial metaplasticity neural network. Expert Systems with Applications, 38(8), 9573-9579.

Miller L. and Ramsey N., 1996. The detection of malignant masses by nonlinear multiscale analysis, in Proc. 3rd Int.Workshop Digital Mammography, K.
Doi, M. L. Giger, R. M. Nishikawa, and R. A. Schmidt, Eds., Chicago, IL, June 9-12, 335-340.

Ojala, T., Pietikinen, M., and Harwood,D., 1996. A comparative study of texture measures with classification based on featured distrubition, Pattern Recognition, 29, no. 1.

Petrick N., Chan H. P., Sahiner B., and Wei D., 1996. An adaptive densityweighted contrast enhancement filter for mammographic breast mass detection, IEEE Trans. Med. Imag.,15, 59-67.

Singh, S. P., and Urooj, S, 2016. An improved CAD system for breast cancer diagnosis based on generalized pseudo-Zernike moment and Ada-DEWNN classifier. Journal of Medical Systems, 40(4), 105.

Smith, R. A., von Eschenbach, A. C., Wender, R., Levin, B., Byers, T., Rothenberger, D., ... \& Eyre, H., 2001. American Cancer Society guidelines for the early detection of cancer: update of early detection guidelines for prostate, colorectal, and endometrial cancers: Also: update 2001-testing for early lung cancer detection. CA: a cancer journal for clinicians, 51(1), 38-75.

Society, A. C., 2019. Breast cancer facts and figures 2019-2020. Atlanta: American Cancer Society, Inc.

Topuz, E. Aydıner, A. Dincer, 2003. M. Meme Kanseri, Nobel Tıp Kitabevi.

Zahran, B., Al-Azzeh, J., Alqadi, Z., Al-Zoghoul, M. A., \& Khawatreh, S., 2018. A Modified Lbp Method to Extract Features from Color Images. Journal of Theoretical \& Applied Information Technology, 96(10).

Xie, W., Li, Y., and Ma, Y., 2016. Breast mass classification in digital mammography based on extreme learning machine. Neurocomputing, 173, 930-941. 